\title{
Associação de Características de Planta em Cultivares de Aveia COM Habilidade Competitiva ${ }^{1}$
}

\author{
Association of Plant Traits in Oat Cultivars with Competitive Ability
}

\author{
FLECK, N.G. ${ }^{2}$, SCHAEDLER, C.E. ${ }^{3}$, AGOSTINETTO, D. ${ }^{2}$, RIGOLI, R.P. ${ }^{4}$, DAL MAGRO, T. ${ }^{5} \mathbf{e}$ \\ TIRONI, S.P. ${ }^{6}$
}

\begin{abstract}
RESUMO - Características morfológicas de plantas cultivadas que confiram maior habilidade competitiva podem integrar medidas de manejo cultural de plantas daninhas e, com isso, reduzir o uso de herbicidas. O objetivo deste trabalho foi investigar se o crescimento inicial por plantas de cultivares de aveia se associa ao seu potencial competitivo com plantas infestantes. Para isso, foi conduzido um experimento a campo na Universidade Federal de Pelotas, em Capão do Leão-RS, durante a estação de crescimento de 2006. Compararam-se os cultivares de aveia: ALBASUL, CFT 1, UPFA 22 e URS 22, os quais foram testados sob três condições de competição (ausência de plantas concorrentes, presença de trigo ou de linho, como competidores). O delineamento experimental utilizado foi completamente casualizado, com quatro repetições. Avaliaram-se diversas características morfológicas em plantas de aveia no início do ciclo de desenvolvimento e outras caracteristicas agronômicas no final do ciclo da aveia e de seus competidores. Os cultivares de aveia responderam diferentemente à presença de plantas competidoras. O cultivar UPFA 22, em geral, apresentou maiores valores para características morfológicas de planta associadas com habilidade competitiva, enquanto o cultivar URS 22, ao contrário, mostrou deficiências em características vantajosas à competição. Os cultivares UPFA 22 e CFT 1 demonstraram elevada capacidade de competir com as espécies concorrentes. Características morfológicas em plantas de cultivares de aveia no início do ciclo de desenvolvimento, de modo geral, não mostraram habilidade competitiva até o final do ciclo.
\end{abstract}

Palavras-chave: Avena sativa, plantas daninhas, interferência, competição.

\begin{abstract}
Morphological crop plant traits which confer greater competitive ability may integrate cultural weed management measures, thus reducing the use of herbicides. The aim of this study was to investigate whether a fast initial growth of oat cultivars relate to their competitive potential with concurrent plants. A field experiment was conducted at the Universidade Federal de Pelotas, in Capão do Leão-RS, during the 2006 growing season. The oat cultivars ALBASUL, CFT 1, UPFA 22 , and URS 22, which were tested under three competition conditions (absence of concurrent plants, presence of flax or of wheat as competitors) were used. The experiment was arranged in a completely randomized design, with four replicates. Many morphological characteristics in oat plants were evaluated at the initial phase of their development, as well as other agronomic traits at the end of the oat cycle and of the cycle of its competitors. Oat cultivars reacted differently to the presence of concurrent plants. The UPFA 22 cultivar generally presented greater values for the morphological plant traits associated with competitive ability; whereas URS 22 showed deficiencies in traits advantageous to competition. The cultivars UPFA 22 and CFT 1 demonstrated a high potential to compete with concurrent plants. The morphological traits of oat cultivars evaluated at the beginning of their development, in general, did not sustain the competitive ability until the end of their cycles.
\end{abstract}

Keywords: Avena sativa, weeds, interference, competition.

1 Recebido para publicação em 9.7.2008 e na forma revisada em 5/6/2009.

2 Engo-Agr ${ }^{0}$, Professor do Dep. de Fitossanidade, Faculdade de Agronomia Eliseu Maciel da Universidade Federal de Pelotas FAEM/UFPel, Bolsista de Produtividade em Pesquisa do CNPq; ${ }^{3}$ Engo-o-Agr ${ }^{\circ}$, Aluno do Programa de Pós-Graduação em Fitossanidade -FAEM/UFPel, <caduschaedler@yahoo.com.br>; ${ }^{4}$ Bióloga, Mestranda do Programa de Pós-Graduação em Fitossanidade - FAEM/ UFPel; ${ }^{5}$ Eng -Agr ${ }^{\mathrm{a}}$, Doutoranda do Programa de Pós-Graduação em Fitossanidade - FAEM/UFPel; ${ }^{6}$ Doutorando do Programa de Pós-Graduação em Fitotecnia - DFT/UFV, Viçosa-MG.

Planta Daninha, Viçosa-MG, v. 27,n. 2, p. 211-220, 2009 


\section{INTRODUÇÃO}

A competição entre plantas é um exemplo de interação negativa, na qual os indivíduos envolvidos disputam recurso(s) que se encon$\operatorname{tra}(\mathrm{m})$ em suprimento escasso, resultando em prejuízo mútuo ao crescimento (Radosevich et al., 1997). A competição entre plantas ocorre quando um (ou mais) dos recursos necessários ao desenvolvimento e crescimento delas se encontra em quantidade limitada para atender às necessidades de todos os indivíduos presentes no meio. Pode ocorrer competição intra e/ou interespecífica - uma podendo ser mais representativa que a outra, dependendo do nicho que cada espécie ocupa no ecossistema que dividem (Passini, 2001; Sobkowicz \& Tendziagolska, 2005).

A presença de plantas daninhas em lavouras de aveia afeta o desenvolvimento da cultura, geralmente causando redução na produção de grãos. Todavia, as perdas de produtividade decorrentes da competição entre plantas costumam ser mais elevadas quanto mais semelhantes forem os individuos, alcançando estresse máximo dentro da mesma espécie (Radosevich et al., 1997). Plantas vizinhas tendem a ocupar o mesmo nicho ecológico, disputando acirradamente os recursos. Entretanto, em competição interespecífica, geralmente as espécies separam a ocupação do nicho no espaço e/ou no tempo. Quanto maior for a população de plantas da comunidade infestante, maior será a quantidade de indivíduos a disputar os recursos do meio e mais intensa será a competição exercida na cultura. Além disso, espécies que sejam morfológica e/ou fisiologicamente próximas costumam apresentar exigências semelhantes em relação aos recursos, tornando mais intensa a competição (Silva \& Durigan, 2006).

Na cultura da aveia, a interferência exercida por plantas daninhas constitui-se em fator responsável por perdas na produtividade de grãos (Comissão..., 2003, 2006). O ciclo da cultura da aveia no Brasil, durante a estação fria, coincide com o de diversas espécies daninhas magnoliopsidas, como cipó-de-veado (Polygonum convolvulus), nabo-forrageiro (Raphanus sativus), nabiça (Raphanus raphanistrum) e serralha (Sonchus oleraceus), e, ainda, com o de poáceas, como azevém
(Lolium multiflorum) e aveia-preta (Avena strigosa). Para eliminação dessas plantas daninhas, dispõe-se de diferentes alternativas, incluindo métodos culturais, mecânicos e químicos, sendo o último o mais utilizado, devido à eficiência que apresenta.

No contexto atual, cada vez mais se faz necessário o desenvolvimento de alternativas de manejo que possam minimizar a dependência do emprego de herbicidas sem afetar a eficiência no controle das plantas daninhas. Um método de manejo cultural econômico e ambientalmente seguro refere-se à utilização de cultivares de aveia com características morfofisiológicas que confiram habilidade competitiva superior à das plantas daninhas, especialmente quando estas se associam à rapide $z$ de germinação e de crescimento inicial (Goldberg \& Landa, 1991).

A identificação de características de planta que confiram maior habilidade competitiva pode ser peça-chave na redução do uso intensivo de agrotóxicos. Existe um potencial elevado para criação de novos cultivares que apresentem habilidade competitiva superior, reduzindo, dessa maneira, a dependência aos herbicidas (Lemerle et al., 1996).

Nesse contexto, evidencia-se a importância de se avaliarem características morfológicas em plantas de cultivares de aveia que se associem à habilidade em competir com plantas daninhas. A hipótese delineada para esta pesquisa é de que cultivares de aveia que apresentam elevada velocidade de crescimento inicial e rápida cobertura do solo se estabelecem mais rapidamente e têm mais sucesso em competir com plantas concorrentes. Em decorrência disso, o objetivo desta pesquisa foi investigar se o crescimento inicial e a cobertura do solo propiciada por diferentes cultivares de aveia se associam ao potencial competitivo com plantas infestantes.

\section{MATERIAL E MÉTODOS}

Um experimento foi conduzido em condição de campo durante a estação de crescimento de 2006, no Centro Agropecuário da Palma (CAP), na Universidade Federal de Pelotas (UFPel), município de Capão do Leão, Rio Grande do Sul, Brasil. O solo foi classificado como Argissolo Vermelho-Amarelo, de textura 
franco-arenosa (Embrapa, 1999). As principais características físico-químicas do solo, resultantes de análise laboratorial realizada 40 dias antes da instalação do experimento, foram: argila, 16\%; $\mathrm{pH}, 5,2$ (em água); índice SMP, 6,5; MO, 1,7\%; P, $35 \mathrm{mg} \mathrm{L}^{-1}$; K, $74 \mathrm{mg} \mathrm{L}^{-1}$; $\mathrm{Al}$, $0,1 \mathrm{cmol}_{\mathrm{c}} \mathrm{L}^{-1} ; \mathrm{Ca}, 2,5 \mathrm{cmol}_{\mathrm{c}} \mathrm{L}^{-1} ; \mathrm{Mg}, 0,8 \mathrm{cmol}_{\mathrm{c}} \mathrm{L}^{-1}$; e CTC efetiva, $4,5 \mathrm{cmol}_{c} \mathrm{~L}^{-1}$.

Para execução do estudo, foram utilizados quatro cultivares de aveia com características morfológicas distintas: ALBASUL, CFT 1, UPFA 22 e "URS 22. Os cultivares ALBASUL e URS 22 apresentaram estatura e cobertura do solo baixa, enquanto CFT 1 e UPFA 22 mostraram elevadas estatura e cobertura (Schaedler, 2008). Eles foram usados como reagentes à interferência de trigo e linho, que simularam espécies daninhas das classes liliopsidas e magnoliopsidas, respectivamente. O cultivar de trigo utilizado como simulador foi Ônix, e o cultivar de linho não foi identificado. A escolha de espécies cultivadas como competidoras visou a obtenção de uniformidade no tempo e no espaço do estabelecimento das populações de plantas na área.

O delineamento experimental utilizado foi blocos casualizados, com parcelas subdivididas, com quatro repetições. Três condições de competição foram locadas nas parcelas principais (ausência de plantas concorrentes, presença de trigo ou presença de linho), e os quatro cultivares de aveia foram locados nas subparcelas. Adicionalmente, foram acrescentados tratamentos comparativos (testemunhas), contendo apenas trigo ou linho, com quatro repetições para cada uma dessas espécies. Cada unidade experimental mediu $5,66 \mathrm{~m}^{2}(1,53 \times 3,7 \mathrm{~m})$, constando de nove fileiras de aveia com $3,7 \mathrm{~m}$, espaçadas de $0,17 \mathrm{~m}$, com área útil disponivel de $2,72 \mathrm{~m}^{2}(1,36 \times 2,0 \mathrm{~m})$.

Antecedendo às semeaduras, foi realizada dessecação química da cobertura vegetal da área, a fim de eliminar as plantas daninhas existentes. No caso, utilizou-se o herbicida glyphosate, aplicado na dose de $900 \mathrm{~g} \mathrm{ha}^{-1}$. Posteriormente, para eliminar plantas emergidas de nabo, usou-se o herbicida metsulfuronmethyl, aplicado na dose de $4 \mathrm{~g}$ i.a. ha ${ }^{-1}$. Por sua vez, plantas de azevém que se estabeleceram na área foram arrancadas manualmente. As semeaduras dos cultivares de aveia e das espécies competidoras ocorreram no dia 29 de junho de 2006, utilizando-se semeadora regulada para distribuir cerca de 350 sementes viáveis $\mathrm{m}^{-2}$. $\mathrm{O}$ trigo foi semeado em fileiras (18) perpendiculares às de aveia, obtendo-se população média de 122 plantas $\mathrm{m}^{-2}$. Por sua vez, o linho foi semeado a lanço, na densidade de $25 \mathrm{~kg}$ de sementes ha ${ }^{-1}$, obtendo-se população média de 162 plantas $\mathrm{m}^{-2}$. A adubação da área foi realizada segundo resultado de análise de solo, seguindo-se as recomendações técnicas preconizadas para a cultura da aveia (Comissão..., 2003).

As características avaliadas nos cultivares de aveia foram: comprimento e largura da primeira folha, cobertura do solo, indice de potencial competitivo, estatura de planta, produtividade de grãos e índice de uso eficiente da terra (UET). Calcularam-se, ainda, as reduções percentuais das produtividades de grãos de aveia e das espécies concorrentes.

O comprimento e a largura da primeira folha foram medidos aos 14 e 28 dias após a emergência (DAE), em dez plantas por unidade experimental, escolhidas aleatoriamente. Para se obter a área foliar, foi utilizado fator de correção de 0,75 , com base em trabalhos anteriores que objetivaram estimar a área foliar de espécies poáceas (Bianco et al., 2000, 2005).

Para estimar o potencial competitivo dos cultivares de aveia, quando do surgimento do primeiro nó, adaptou-se escala proposta por Lemerle et al. (2001). A avaliação foi realizada de forma visual, utilizando-se características de planta, como: estatura, vigor, largura e inclinação das folhas, afilhamento e cobertura do solo. Essa avaliação foi feita por dois avaliadores, que atuaram de modo independente e atribuíram notas individuais, variáveis de 1 a 5 , as quais foram posteriormente combinadas para obtenção das respectivas médias. Essa característica foi determinada apenas nas parcelas com ausência de plantas competidoras.

A cobertura foliar do solo pelo dossel dos cultivares foi avaliada aos 14 e $28 \mathrm{DAE}$, por meio dos métodos visual e fotográfico. Na avaliação visual utilizou-se, como critério, escala percentual, em que a nota zero correspondeu à ausência de cobertura do solo pelo dossel das 
plantas e a nota 100 significou cobertura completa do solo. Para se proceder à avaliação fotográfica, foram usadas duas áreas de $0,25 \mathrm{~m}^{2}$ em cada unidade experimental. Com auxilio de programa computacional, as fotos foram digitalizadas, para permitir a diferenciação da folhagem das plantas em relação ao solo. Posteriormente, foi estimada, com auxílio do programa Sigma Scan, a participação da área ocupada pela parte aérea das plantas em relação à área total amostrada.

Por ocasião da colheita das panículas dos cultivares, realizada aos 132 DAE, determinou-se a produtividade de grãos de aveia em área útil de $2,72 \mathrm{~m}^{2}$, a qual englobou as sete fileiras centrais das subparcelas. Após pesagem dos grãos, determinou-se sua umidade, e as massas foram corrigidas para $13 \%$ de umidade, sendo expressas em $\mathrm{kg} \mathrm{ha}^{-1}$.

A partir da produtividade de grãos dos cultivares de aveia e das espécies competidoras, calculou-se o indice de uso eficiente da terra (UET), com o objetivo de estabelecer os graus de complementaridade entre os cultivares associados e sua participação relativa na produtividade total de grãos, quando em associação. Nesse sentido, utilizou-se a equação referida por Radosevich et al. (1997): UET $=\mathrm{UET}_{\mathrm{r}}$ $+\mathrm{UET}_{\mathrm{s}}$, sendo: $\mathrm{UET}_{\mathrm{r}}=\mathrm{PR}_{\mathrm{A}} / \mathrm{PR}_{\mathrm{M}}$ e $\mathrm{UET}_{\mathrm{s}}=\mathrm{PS}_{\mathrm{A}} /$ $\mathrm{PS}_{\mathrm{M}}$. No caso, tem-se: UET $\mathrm{r}_{\mathrm{r}}=\mathrm{UET}$ parcial do cultivar reagente; $\mathrm{PR}_{\mathrm{A}}=$ produtividade de grãos do cultivar reagente $(R)$ quando em associação; $\mathrm{PR}_{\mathrm{M}}=$ produtividade de grãos do cultivar $\mathrm{R}$ quando em monocultivo; $\mathrm{UET}_{\mathrm{s}}=\mathrm{UET}$ parcial da espécie simuladora; $\mathrm{PS}_{\mathrm{A}}=$ produtividade de grãos da espécie simuladora $(\mathrm{S})$ quando $\mathrm{em}$ associação; e $\mathrm{PS}_{\mathrm{M}}=$ produtividade de grãos da cultura $\mathrm{S}$ quando em monocultivo. Para se obter a contribuição relativa de cada cultivar reagente para o UET total da respectiva associação, dividiu-se o UET pelo UET, expressando-se os valores em porcentagem.

Os dados obtidos foram analisados quanto à homocedasticidade e, posteriormente, procedeu-se à análise de variância, através do teste F (SAS, 1989), adotando-se como limite de aceitação de significância $5 \%$ de probabilidade, tanto para efeitos individuais dos fatores como para efeitos de interação. A partir dos dados obtidos para a variável produtividade de grãos dos cultivares reagentes, também foram calculadas perdas $(\mathrm{P})$ percentuais, relativamente às parcelas testemunhas (ausência de espécies concorrentes). Para esses cálculos, usou-se a equação: $\mathrm{P}(\%)=$ $\left(\mathrm{P}_{\mathrm{a}}-\mathrm{P}_{\mathrm{p}} / \mathrm{Pa}\right) \times 100$, em que: $\mathrm{P}_{\mathrm{a}}$ e $\mathrm{P}_{\mathrm{p}}=$ produtividades do cultivar de aveia na ausência e na presença de espécies simuladoras de plantas concorrentes, respectivamente.

\section{RESULTADOS E DISCUSSÃO}

Para as variáveis comprimento e largura da primeira folha, houve diferenças para os cultivares de aveia nas duas épocas avaliadas (Tabela 1). O cultivar ALBASUL apresentou valores inferiores para comprimento, porém ele não diferiu de URS 22. Já o cultivar UPFA 22 e o CFT 1 foram os que apresentaram maiores valores para esta variável. No entanto, consideradas as duas épocas, o cultivar UFPA 22 apresentou menor largura da primeira folha, quando comparado ao cultivar ALBASUL. O produto dessas duas variáveis, que definem a área foliar aproximada, não apresentou diferenças entre os cultivares, denotando uma compensação entre as duas medidas.

Tabela 1 - Comprimento (C) e largura (L) da primeira folha e seu produto, em plantas de cultivares de aveia aos 14 e 28 dias após a emergência (DAE). Capão do Leão-RS, 2006

\begin{tabular}{|c|c|c|c|}
\hline \multirow[b]{2}{*}{ Cultivar } & \multicolumn{3}{|c|}{$14 \mathrm{DAE}$} \\
\hline & $\begin{array}{c}\text { Comprimento } \\
(\mathrm{cm})\end{array}$ & Largura $(\mathrm{cm})$ & $\begin{array}{c}\mathrm{C} \times \mathrm{L} \times(0,75)^{1} \\
\left(\mathrm{~cm}^{2}\right)\end{array}$ \\
\hline ALBASUL & $9,3 \mathrm{~b}^{2 /}$ & $0,50 \quad \mathrm{a}$ & 3,5 ns \\
\hline CFT 1 & 11,1 a & $0,50 \quad \mathrm{a}$ & 4,2 \\
\hline UPFA 22 & $11,1 \quad \mathrm{a}$ & $0,42 \mathrm{~b}$ & 3,5 \\
\hline URS 22 & $10,0 \quad \mathrm{ab}$ & $0,52 \quad \mathrm{a}$ & 3,9 \\
\hline Médias & 10,4 & 0,49 & 3,8 \\
\hline $\mathrm{CV}(\%)$ & 5,9 & 6,9 & 10,8 \\
\hline \multirow[b]{2}{*}{ Cultivar } & \multicolumn{3}{|c|}{$28 \mathrm{DAE}$} \\
\hline & $\begin{array}{c}\text { Comprimento } \\
(\mathrm{cm})\end{array}$ & Largura $(\mathrm{cm})$ & $\begin{array}{c}\mathrm{C} \times \mathrm{L} \times(0,75) \\
\left(\mathrm{cm}^{2}\right)\end{array}$ \\
\hline ALBASUL & $9,3 \mathrm{c}$ & $0,56 \mathrm{a}$ & $3,9^{\mathrm{ns}}$ \\
\hline CFT 1 & $11,0 \mathrm{ab}$ & $0,52 \mathrm{ab}$ & 4,3 \\
\hline UPFA 22 & $11,6 \mathrm{a}$ & $0,49 \mathrm{~b}$ & 4,3 \\
\hline URS 22 & $10,1 \mathrm{bc}$ & $0,54 \mathrm{ab}$ & 4,1 \\
\hline Médias & 10,6 & 0,53 & 4,1 \\
\hline $\mathrm{CV}(\%)$ & 6,9 & 5,6 & 11,0 \\
\hline
\end{tabular}

1/ Fator de correção, de acordo com Bianco et al. (2000, 2005)

2/Médias seguidas por letras distintas, comparadas nas colunas, diferem pelo teste de Duncan $(\mathrm{p} \leq 0,05)$. ${ }^{\text {ns }}$ Não-significativo pelo teste $\mathrm{F}(\mathrm{p} \leq 0,05)$. 
Houve diferenças para o potencial competitivo dos cultivares de aveia (Tabela 2). UPFA 22 e URS 22 apresentaram o maior e o menor indice, respectivamente. Além disso, CFT 1 não diferiu de UPFA 22, nem ALBASUL diferiu de URS 22.

Os cultivares diferiram quanto à cobertura do solo somente aos 28 e $42 \mathrm{DAE}$, em ambos os métodos utilizados (Tabela 3). Nessas duas épocas, os cultivares que, em geral, apresentaram maior e menor cobertura do solo, respectivamente, foram UPFA 22 e ALBASUL. Os cultivares CFT 1 e URS 22, em geral, apresentaram valores intermediários. Vale apontar que, em média, o método fotográfico estimou maiores coberturas aos 28 e $42 \mathrm{DAE}$ do que o visual (acréscimos de 57 e 18\%, respectivamente).

Os resultados referentes à estatura de plantas dos cultivares avaliados encontramse na Tabela 4. Não houve efeitos significativos para a interação cultivares $\mathrm{x}$ condições

Tabela 2 - Índice de potencial competitivo de cultivares de aveia, avaliado visualmente, aos 42 dias após a emergência. Capão do Leão-RS, 2006

\begin{tabular}{|l|l|}
\hline Cultivar & Índice $^{\underline{1}}$ \\
\hline ALBASUL & $2,8 \mathrm{bc}^{2^{\prime}}$ \\
CFT 1 & $3,4 \mathrm{ab}$ \\
UPFA 22 & $3,9 \mathrm{a}$ \\
URS 22 & $2,3 \mathrm{c}$ \\
\hline Média & 2,1 \\
\hline CV (\%) & 11,8 \\
\hline
\end{tabular}

1/ Segundo escala proposta por Lemerle et al. (2001). ㄹ/ Médias seguidas por letras distintas diferem pelo teste de Duncan $(\mathrm{p} \leq 0,05)$. de competição. Aos 14 DAE, os cultivares CFT 1 e UPFA 22 apresentaram estaturas superiores às de ALBASUL e URS 22. Já a partir dos 28 DAE, somente URS 22 mostrou estatura inferior à dos demais cultivares. O cultivar UPFA 22 apresentou maior estatura de planta até o final do ciclo. Esses resultados denotam respostas específicas dos cultivares às condições de ambiente onde foram testados; não necessariamente tais respostas podem se repetir em outras condições de clima e/ou de solo.

A produtividade de grãos dos cultivares de aveia mostrou efeito significativo para interação cultivares $\mathrm{x}$ condições de competição (Tabela 5). Os cultivares que apresentaram maiores potenciais produtivos foram ALBASUL e URS 22, quando em monocultivo, superando UPFA 22. Nenhum cultivar de aveia sofreu redução significativa quando associado ao linho; contudo, todos apresentaram produção reduzida quando associados ao trigo. Em valores absolutos, geralmente, o cultivar ALBASUL se posicionou com as maiores produtividades, enquanto UPFA 22, ao contrário, geralmente, mostrou as menores produtividades. Já CFT 1 e URS 22 apresentaram comportamentos variáveis, segundo a condição de competição. Por exemplo, em associação ao trigo, URS 22 sofreu redução de produtividade mais drástica do que CFT 1.

Em termos de reduções percentuais de produtividade de grãos, houve efeito significativo para a interação cultivares de aveia x espécies competidoras (Tabela 6). Para os cultivares avaliados, ocorreu maior redução de produtividade quando estes estiveram associados ao

Tabela 3 - Cobertura do solo (\%) formada por plantas de cultivares de aveia, avaliada através de dois métodos, aos 14, 28 e 42 dias após a emergência (DAE). Capão do Leão-RS, 2006

\begin{tabular}{|c|c|c|c|c|c|c|}
\hline \multirow{2}{*}{ Cultivar } & \multicolumn{2}{|c|}{$14 \mathrm{DAE}$} & \multicolumn{2}{|c|}{$28 \mathrm{DAE}$} & \multicolumn{2}{|c|}{$42 \mathrm{DAE}$} \\
\hline & Visual & Fotográfico & Visual & Fotográfico & Visual & Fotográfico \\
\hline ALBASUL & $18^{\mathrm{ns}}$ & $18^{\mathrm{ns}}$ & $29 \mathrm{~d}^{1 /}$ & $51 \mathrm{~b}$ & $58 \mathrm{c}$ & $79 \mathrm{c}$ \\
\hline CFT 1 & 19 & 20 & $35 \mathrm{c}$ & $64 \mathrm{a}$ & $74 \mathrm{~b}$ & $87 \mathrm{ab}$ \\
\hline UPFA 22 & 23 & 21 & $46 \mathrm{a}$ & $63 a$ & $86 \mathrm{a}$ & $94 \mathrm{a}$ \\
\hline URS 22 & 23 & 19 & $40 \mathrm{~b}$ & $56 \mathrm{ab}$ & $72 \mathrm{~b}$ & $84 \mathrm{bc}$ \\
\hline Médias & 21 & 20 & 37 & 58 & 73 & 86 \\
\hline $\mathrm{CV}(\%)$ & 18,9 & 23,0 & 4,6 & 12,6 & 4,5 & 3,7 \\
\hline
\end{tabular}

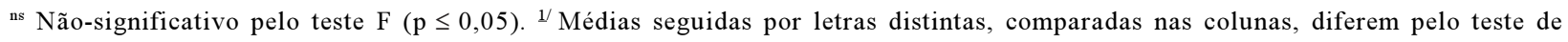
Duncan $(\mathrm{p} \leq 0,05)$. 
trigo. Em associação ao linho, os cultivares reduziram a produtividade em $6 \%$, em média; associados ao trigo, a redução alcançou $30 \%$. $\mathrm{O}$ cultivar que apresentou maiores reduções percentuais de produtividade foi URS 22, por efeito de ambas as espécies competidoras.

Tabela 4 - Estatura (cm) de plantas de cultivares de aveia, avaliada aos 14, 28 e 42 dias após a emergência (DAE) e na précolheita. Capão do Leão-RS, 2006

\begin{tabular}{|l|c|c|c|c|}
\hline \multicolumn{1}{|c|}{ Cultivar } & 14 DAE & 28 DAE & 42 DAE & Pré-colheita \\
\hline ALBASUL & $14,3 \mathrm{~b}^{-\frac{1}{}}$ & $30,8 \mathrm{a}$ & $39,9 \mathrm{a}$ & $108 \mathrm{c}$ \\
CFT 1 & $16,4 \mathrm{a}$ & $32,8 \mathrm{a}$ & $40,2 \mathrm{a}$ & $116 \mathrm{~b}$ \\
UPFA 22 & $16,4 \mathrm{a}$ & $32,3 \mathrm{a}$ & $45,5 \mathrm{a}$ & $122 \mathrm{a}$ \\
URS 22 & $14,7 \mathrm{~b}$ & $26,9 \mathrm{~b}$ & $31,5 \mathrm{~b}$ & $100 \mathrm{~d}$ \\
\hline Médias & 15,5 & 30,7 & 39,3 & 112 \\
\hline CV (\%) & 5,5 & 8,6 & 9,1 & 3,8 \\
\hline
\end{tabular}

${ }^{1 /}$ Médias seguidas por letras distintas, comparadas nas colunas, diferem pelo teste de Duncan $(\mathrm{p} \leq 0,05)$.

Tabela 5 - Produtividade de grãos $\left(\mathrm{kg} \mathrm{ha}^{-1}\right)$ de cultivares de aveia, em função de condições de competição com linho ou trigo. Capão do Leão-RS, 2006

\begin{tabular}{|l|c|c|c|}
\hline \multirow{2}{*}{ Cultivar } & \multicolumn{3}{|c|}{ Condição de competição } \\
\cline { 2 - 4 } & Aveia solteira & $\begin{array}{c}\text { Associada ao } \\
\text { linho }\end{array}$ & $\begin{array}{c}\text { Associada ao } \\
\text { trigo }\end{array}$ \\
\hline ALBASUL & A $4.742 \mathrm{a}^{1 /}$ & AB $4.519 \mathrm{a}$ & B $4.120 \mathrm{a}$ \\
CFT 1 & A $4.432 \mathrm{ab}$ & A $4.437 \mathrm{a}$ & B $3.354 \mathrm{~b}$ \\
UPFA 22 & A $3.947 \mathrm{~b}$ & A $3.735 \mathrm{~b}$ & B $2.580 \mathrm{c}$ \\
URS 22 & A $4.569 \mathrm{a}$ & A $4.096 \mathrm{ab}$ & B $2.456 \mathrm{c}$ \\
\hline Médias & 4.423 & 4.197 & 3.128 \\
\hline CV (\%) & & 9,0 & \\
\hline
\end{tabular}

1/ Médias seguidas por letras distintas, minúsculas comparadas nas colunas e maiúsculas comparadas nas linhas, diferem pelo teste de Duncan $(\mathrm{p} \leq 0,05)$.

Tabela 6 - Reduções percentuais médias de produtividade de grãos de cultivares de aveia quando associados com linho ou trigo. Capão do Leão-RS, 2006

\begin{tabular}{|c|c|c|}
\hline Cultivar & $\begin{array}{c}\text { Redução (\%) associada } \\
\text { ao linho }\end{array}$ & $\begin{array}{c}\text { Redução (\%) associada } \\
\text { ao trigo }\end{array}$ \\
\hline ALBASUL & B $5 a^{1}$ & A 14 d \\
\hline CFT 1 & B $1 \quad b$ & A $24 \mathrm{c}$ \\
\hline UPFA 22 & B $5 \mathrm{ab}$ & A $35 \mathrm{~b}$ \\
\hline URS 22 & B 11 a & A 46 a \\
\hline Médias & 6 & 30 \\
\hline $\mathrm{CV}(\%)$ & \multicolumn{2}{|c|}{27,8} \\
\hline
\end{tabular}

${ }^{1 /}$ Médias seguidas por letras distintas, minúsculas comparadas nas colunas e maiúsculas comparadas nas linhas, diferem pelo teste de Duncan $(\mathrm{p} \leq 0,05)$
Com relação às perdas de produtividade de grãos das espécies competidoras, o linho sofreu reduções mais acentuadas, em decorrência de sua associação com os cultivares de aveia, do que ocorreu com trigo (Tabela 7). Os impactos mais negativos à produtividade de linho foram causados pelos cultivares ALBASUL, CFT $1 \mathrm{e}$ UPFA 22 (90\%, em média), contra apenas 79\% na associação de linho a URS 22. Já o trigo foi mais afetado pela presença de UPFA 22. Por outro lado, URS 22 foi o cultivar que ocasionou menor perda de produtividade ao trigo. Os resultados apontam para um potencial competitivo do linho bem inferior ao do trigo, quando ambos estiveram associados e sofreram pressão competitiva dos cultivares de aveia.

$\mathrm{O}$ indice de uso eficiente da terra (UET) para as produtividades combinadas de grãos não variou em função dos cultivares de aveia

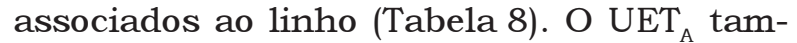
pouco diferiu entre cultivares, variando ao redor de 1,0. Por outro lado, URS 22 foi o que menos afetou o $\mathrm{UET}_{\mathrm{L}}$ do linho, enquanto os demais foram responsáveis pelas maiores quedas no $\mathrm{UET}_{\mathrm{L}}$ do competidor linho. Isso aponta para um baixo potencial competitivo do cultivar URS 22 , já que sua contribuição para o UET foi de apenas $84 \%$.

$\mathrm{O} \mathrm{UET}_{\mathrm{A}}$ variou em função dos cultivares de aveia associados ao trigo, em que ALBASUL contribuiu com a maior parcela para o UET da associação; novamente URS 22 foi pouco competitivo, dando oportunidade ao trigo de produzir mais grãos em sua presença (Tabela 9). Desse modo, este contribuiu pouco para o UET da associação, enquanto o trigo participou com a maior parcela.

Os UETs das associações aveia $\mathrm{x}$ trigo não chegaram a se diferenciar em função do cultivar de aveia associado ao trigo (Tabela 9). Contudo, em valores relativos, o UET da associação trigo x UPFA 22 foi 15\% inferior ao da associação de trigo com ALBASUL. Para o $\mathrm{UET}_{\mathrm{T}}$, o cultivar de aveia URS 22 propiciou condição ao trigo para produzir mais grãos e contribuir mais para o UET da associação. Este cultivar participou com apenas 58\% do UET total, enquanto o ALBASUL, por exemplo, contribuiu com $84 \%$.

Em razão do maior potencial competitivo demonstrado pelo trigo quando associado à 
Tabela 7 - Reduções percentuais das produtividades de grãos de linho ou de trigo, utilizados como competidores, quando associados a cultivares de aveia. Capão do Leão-RS, 2006

\begin{tabular}{|l|c|c|}
\hline Cultivar associado & Redução (\%) do linho & Redução (\%) do trigo \\
\hline ALBASUL & $94 \mathrm{a}^{\mathrm{I}^{-}}$ & $69 \mathrm{bc}$ \\
CFT 1 & $89 \mathrm{a}$ & $78 \mathrm{ab}$ \\
UPFA 22 & $87 \mathrm{a}$ & $82 \mathrm{a}$ \\
URS 22 & $79 \mathrm{~b}$ & $67 \mathrm{c}$ \\
\hline Médias & 87 & 74 \\
\hline CV (\%) & 6,1 & 7,6 \\
\hline
\end{tabular}

1/ Médias seguidas por letras distintas, comparadas nas colunas, diferem pelo teste de Duncan $(\mathrm{p} \leq 0,05)$.

Tabela 8 - Índice de uso eficiente da terra (UET) e contribuições relativas para cultivares de aveia quando associados ao linho como competidor. Capão do Leão-RS, 2006

\begin{tabular}{|c|c|c|c|c|}
\hline $\begin{array}{c}\text { Cultivar } \\
\text { associado }\end{array}$ & \begin{tabular}{|c|} 
UET da \\
associação $^{-1 /}$
\end{tabular} & $\mathrm{UET}_{\mathrm{A}}{ }^{2 /}$ & $\mathrm{UET}_{\mathrm{L}}{ }^{\frac{3}{2}}$ & $\begin{array}{l}\text { Contribuição } \\
\text { relativa }(\%)^{4 /}\end{array}$ \\
\hline ALBASUL & $1,04^{\mathrm{ns}}$ & $0,94^{\mathrm{ns}}$ & $0,10 b^{5 /}$ & $90 \mathrm{a}$ \\
\hline CFT 1 & 1,11 & 1,02 & $0,09 \mathrm{~b}$ & $92 \mathrm{a}$ \\
\hline UPFA 22 & 1,15 & 1,06 & $0,09 \mathrm{~b}$ & $92 \mathrm{a}$ \\
\hline URS 22 & 1,15 & 0,96 & $0,19 \mathrm{a}$ & $84 \mathrm{~b}$ \\
\hline Médias & 1,11 & 0,99 & 0,12 & 90 \\
\hline $\mathrm{CV}(\%)$ & 7,0 & 6,7 & 12,8 & 1,2 \\
\hline
\end{tabular}

$1 / \mathrm{UET}=\mathrm{UET}_{\mathrm{A}}+\mathrm{UET}_{\mathrm{L}}{ }^{2} \stackrel{2}{2} \mathrm{UET}$ parcial do cultivar de aveia em associação com linho. ${ }^{3 /}$ UET parcial do competidor linho em associação. ${ }^{4 /}$ Contribuição relativa do cultivar de aveia para o UET total da associação com linho. ${ }^{\text {ns }}$ Não-significativo pelo teste $\mathrm{F}(\mathrm{p} \leq 0,05) .{ }^{5 /}$ Médias seguidas por letras distintas, comparadas nas colunas, diferem pelo teste de Duncan $(\mathrm{p} \leq 0,05)$.

aveia, em relação ao do linho, constatou-se que, em média, os cultivares de aveia contribuíram com somente $75 \%$ do UET total, enquanto associados ao linho eles alcançaram 90\% de participação.

No caso da associação aveia x linho, houve maior complementaridade no uso de recursos, propiciando UET total médio de 1,10; já na associação aveia $\mathrm{x}$ trigo, o uso de recursos foi mais disputado, ocorrendo menor complementaridade entre as duas espécies, e o UET total médio foi de 0,94 (diferença de 16\% em relação ao primeiro caso). Isso indica que o trigo apresenta maior potencial competitivo do que o linho. Para essa diferença contribuem as variações morfofisiológicas entre as plantas de trigo e linho, que afetam a busca e a repartição dos recursos disponiveis.
Tabela 9 - Índices de uso eficiente da terra (UET) e contribuições relativas para cultivares de aveia quando associados ao trigo como competidor. Capão do Leão-RS, 2006

\begin{tabular}{|c|c|c|c|c|}
\hline $\begin{array}{c}\text { Cultivar } \\
\text { associado }\end{array}$ & $\begin{array}{c}\text { UET da } \\
\text { associação }^{\underline{1}}\end{array}$ & $\mathrm{UET}_{\mathrm{A}} \frac{2 /}{1}$ & $\mathrm{UET}_{\mathrm{L}}{ }^{\frac{3}{}}$ & $\begin{array}{l}\text { Contribuição } \\
\text { relativa }(\%)^{4 /}\end{array}$ \\
\hline ALBASUL & $1,04^{\mathrm{ns}}$ & $0,87 \mathrm{a}^{\frac{5}{}}$ & $0,16 \mathrm{~b}$ & $84 \mathrm{a}$ \\
\hline CFT 1 & 0,94 & $0,76 \mathrm{ab}$ & $0,18 \mathrm{~b}$ & $81 \mathrm{ab}$ \\
\hline UPFA 22 & 0,88 & $0,66 \mathrm{bc}$ & $0,22 \mathrm{~b}$ & $75 \mathrm{~b}$ \\
\hline URS 22 & 0,92 & $0,54 \mathrm{c}$ & $0,39 \mathrm{a}$ & $58 \mathrm{c}$ \\
\hline Médias & 0,94 & 0,71 & 0,24 & 75 \\
\hline $\mathrm{CV}(\%)$ & 10,6 & 13,4 & 23,4 & 13,4 \\
\hline
\end{tabular}

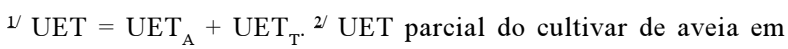
associação com trigo. ${ }^{3 /}$ UET parcial do competidor trigo em associação. ${ }^{4 /}$ Contribuição relativa do cultivar de aveia para o UET total da associação com trigo. ${ }^{5 /}$ Médias seguidas por letras distintas, comparadas nas colunas, diferem pelo teste de Duncan $(\mathrm{p} \leq 0,05) .{ }^{n s}$ Não-significativo pelo teste $\mathrm{F}(\mathrm{p} \leq 0,05)$

Os cultivares de aveia comparados no estudo demonstraram diferenças importantes em relação às características de planta avaliadas na fase inicial de desenvolvimento e que, supostamente, podem desempenhar papel relevante na competição mais tardia com plantas daninhas. Assim, com base nas variáveis relacionadas ao provável potencial de competitividade, os cultivares ALBASUL e URS 22 não mostraram destaques significativos no início do ciclo no mencionado aspecto. Por outro lado, o cultivar UPFA 22 incorporou algumas características típicas de planta competidora, enquanto CFT 1 se distinguiu em poucos aspectos positivos.

Para comprimento e largura da primeira folha dos cultivares testados, ocorreu efeito compensatório nas duas épocas avaliadas (14 e 28 DAE). O cultivar ALBASUL apresentou menor comprimento, e UPFA 22, o maior; já para largura da folha ocorreu o inverso. Resultados obtidos em plantas de trigo que apresentaram maior área da primeira folha, durante a fase inicial de desenvolvimento, mostraram habilidade competitiva superior (Lemerle et al., 2006). No presente estudo não se confirmou essa hipótese, pois uma única característica morfológica apregoada como potencialmente vantajosa para incrementar a capacidade competitiva de determinada cultivar não é totalmente responsável por esse efeito. 
As variações verificadas para a variável estatura de plantas podem decorrer do crescimento rápido em estatura apresentado por alguns cultivares, o qual é uma característica geralmente almejada no processo supressivo de plantas daninhas pelas culturas, visto que thes propicia vantagem na competição pelo recurso luz, possibilitando sombrear espécies concorrentes de menor porte (Ogg Jr. \& Seefeldt, 1999).

Para cobertura do solo formada pelo dossel das plantas de aveia, o cultivar UPFA 22 se destacou, ao apresentar maiores valores em ambos os métodos de avaliação (28 e 42 DAE). $\mathrm{O}$ método visual mostrou-se apropriado para estimar cobertura, sendo procedimento rápido e prático de se adotar, exceto para o cultivar CFT1 aos 28 DAE. Contudo, ele requer treinamento dos avaliadores para que possa ser confiável, quando utilizado em sistemas de manejo de plantas daninhas (Vitta \& Fernandez Quintanilla, 1996). Já o método fotográfico é mais demorado, visto requerer uma sequência de etapas e de cuidados na utilização do programa computacional - por exemplo, o ajuste nas ferramentas de sensibilidade de diferenciação das cores das plantas e do solo. Embora o método seja mais lento que outros, constitui-se em alternativa promissora na quantificação da cobertura vegetal (Rizzardi $\&$ Fleck, 2004). A habilidade competitiva das plantas em interceptar a luz incidente no dossel é uma característica desejável às culturas quando em competição com plantas daninhas (Seavers \& Wright, 1999). No entanto, a capacidade de cobrir o solo depende, além da estatura de planta, de outras características morfológicas, como área foliar e ângulo de inclinação das folhas.

O potencial competitivo de cultivares é uma medida que pode auxiliar na escolha daqueles cultivares que apresentem indice elevado. Nesta pesquisa, a determinação da variável foi realizada em cultivares de aveia que cresceram na ausência de espécies competidoras. Ele representa uma ferramenta adicional de avaliação, pois pode ser usado de forma prática e rápida na escolha de cultivares mais promissores. Os cultivares que apresentaram maior e menor índice de potencial competitivo foram UPFA 22 e URS 22, respectivamente (Tabela 2).
Os cultivares apresentaram variações em produtividade de grãos em função das condições de competição a que foram submetidos. Em geral, na presença do competidor linho, não apresentaram grandes reduções; já na presença do trigo, todos eles sofreram relevantes reduções em produtividade de grãos. Esse resultado pressupõe que as perdas de produtividade em aveia decorrentes da competição com trigo devam-se, sobretudo, à semelhança que ambas as espécies apresentam. Quando os cultivares de aveia competiram com o linho, respondendo com baixas perdas de produtividade, supõe-se que ocorreu separação na ocupação do nicho no espaço e/ou no tempo. Para Radosevich et al. (1997), quanto mais semelhantes, morfologicamente, forem os indivíduos em competição, as perdas de produtividade tendem a ser mais elevadas, alcançando estresse máximo, pois plantas vizinhas tendem a ocupar o mesmo nicho ecológico, disputando, simultaneamente, recursos escassos ao crescimento de ambas.

Para redução de produtividade de grãos, em termos percentuais, o cultivar URS 22, tanto em competição com o linho quanto com trigo, apresentou os maiores decréscimos. Em oposto, o cultivar CFT 1 pode classificar-se como de alta capacidade competitiva, pois apresentou menores perdas de produtividade na presença das duas espécies concorrentes. Quanto à produtividade de grãos (e sua redução) para as espécies concorrentes (linho e trigo), em decorrência da presença de aveia, estas alcançaram maiores produtividades (equivalentes às das testemunhas) e sofreram menores reduções da variável quando associadas à de URS 22. Isso demonstra que este cultivar apresenta baixa capacidade competitiva. Ainda, para este cultivar, observou-se antecipação de cerca de cinco dias no florescimento quando em condição de competição. Nesse sentido, evidencia-se que o processo de aceleração do florescimento pode ser uma reação ao estresse que o cultivar sofreu. URS 22 demonstrou baixa tolerância à presença das concorrentes, pois foi o cultivar que apresentou maior redução em produtividade, independentemente da espécie competidora presente. Comportamento semelhante ao de produtividade de grãos foi observado para índice de uso eficiente da terra parcial para os cultivares. Nesse aspecto, o cultivar que menos 
afetou o UET dos competidores linho e trigo foi URS 22, resultando, também, em baixa contribuição relativa deste ao consórcio.

O cultivar ALBASUL, em geral, não apresentou características iniciais desejáveis a uma planta competitiva, como rapidez de crescimento em estatura, formação de um dossel que propiciasse rápida cobertura do solo e acúmulo acelerado de massa na parte aérea. No entanto, especula-se que possa ter ocorrido competição por recursos disponibilizados no solo, visto que ALBASUL se mostrou relativamente tolerante aos competidores linho e trigo, apresentando produtividades maiores do que as dos demais cultivares. Suspeita-se, também, da possibilidade de liberação de aleloquímicos desse cultivar às espécies concorrentes. Em estudo que avaliou o potencial alelopático de cultivares de aveia no início do ciclo, encontraram-se diferenças entre eles (Jacobi \& Fleck, 2000). Nesta pesquisa, os efeitos produzidos pelo composto escopoletina foram semelhantes aos dos aleloquímicos liberados pelos próprios cultivares de aveia, mostrando semelhança entre os efeitos alelopáticos produzidos pela substância sintética e o provocado pelos cultivares. No caso do cultivar CFT 1, este apresentou comportamento diferenciado quando associado às espécies competidoras: suprimiu o competidor linho, enquanto teve sua produtividade reduzida pelo trigo.

Dificilmente uma única característica morfológica conferirá elevado potencial competitivo às plantas de um cultivar (Lemerle et al., 1996). Assim, o cultivar UPFA 22 destacou-se positivamente, englobando várias características favoráveis à habilidade competitiva, que the conferiram, neste estudo, poder de suprimir os competidores, enquanto para URS 22 se verificou o contrário.

Em decorrência dos dados obtidos para as diversas variáveis avaliadas nesta pesquisa, pode-se inferir que as características morfológicas estudadas no início do ciclo de desenvolvimento dos quatro cultivares de aveia não apresentam associação ou contribuição relevante para o potencial competitivo posterior destes com plantas infestantes. É provável que as variáveis avaliadas, basicamente relacionadas ao ambiente do estrato aéreo das plantas, não espelhem toda a natureza envolvida na competição entre as espécies em questão e que a concorrência por recursos do solo possa ser mais importante do que inicialmente suposto. Adicionalmente, é fundamental que um cultivar que, no início do desenvolvimento, mostre características vantajosas quanto ao potencial competitivo consiga sustentá-las até o final do ciclo, sob pena de elas perderem sua importância.

Em relação à produtividade de grãos, o cultivar ALBASUL demonstrou perfil plenamente vantajoso, enquanto UPFA 22, por outro lado, deixou a desejar, pois, além do potencial produtivo relativamente baixo em monocultivo, sofreu reduções relevantes da variável quando em condição de competição. Já CFT 1 manteve um comportamento intermediário ao daqueles dois. Ele apresentou produtividade adequada quando cultivado sozinho ou associado ao linho; contudo, em presença de trigo, sofreu decréscimo importante da variável. URS 22, por sua vez, apresenta elevado potencial produtivo, mas apenas quando em cultivo isolado; uma vez em presença de plantas concorrentes, sua produtividade de grãos decaiu acentuadamente. Talvez este represente um caso mais típico, em que características iniciais desfavoráveis se refletiram negativamente até o final do seu ciclo.

Os cultivares de aveia respondem diferentemente à presença de plantas competidoras, indicando que existe variabilidade em caracteres de planta, o que possibilita selecionar geneticamente cultivares de aveia com habilidade competitiva superior. O cultivar UPFA 22, em geral, apresenta maiores valores para características morfológicas de planta indicadoras de habilidade competitiva, como cobertura do solo, estatura de planta e potencial competitivo, enquanto o cultivar URS 22 carece de características iniciais favoráveis à capacidade competitiva. Os cultivares UPFA 22 e CFT 1 demonstram exercer elevada capacidade de competir com espécies concorrentes. Características morfológicas de cultivares de aveia, avaliadas no início do ciclo de desenvolvimento, em geral, não mostram associação com potencial competitivo durante todo o ciclo.

Assim, tanto em presença de linho quanto de trigo, o cultivar de aveia URS 22 demonstrou o menor potencial competitivo entre os 
quatro que foram comparados. Especificamente quando associados ao linho, representando uma espécie concorrente magnoliopsida, os cultivares ALBASUL, CFT 1 e UPFA 22 apresentaram desempenhos equivalentes. Já na presença de trigo, representando uma espécie concorrente liliopsida, a capacidade competitiva de ALBASUL superou aquela apresentada pelo cultivar UPFA 22.

\section{LITERATURA CITADA}

BIANCO, S. et al. Estimativa da área foliar de plantas daninhas Brachiaria decumbens Stapf. e Brachiaria brizantha (Hochst.) Stapf. Planta Daninha, v. 18, n. 1, p. 79-83, 2000.

BIANCO, S.; PITELLI, R. A.; BIANCO, M. S. Estimativa da área foliar de Brachiaria plantaginea usando dimensões lineares do limbo foliar. Planta Daninha, v. 23, n. 4, p. 597-601, 2005.

COMISSÃO BRASILEIRA DE PESQUISADE AVEIACBPA. Indicações técnicas para a cultura da aveia (grãos e forrageira). Passo Fundo: UPF-UFRGS, 2003. 86 p.

COMISSÃO BRASILEIRA DE PESQUISADE AVEIACBPA. Indicações técnicas para a cultura da aveia. Guarapuava: Fundação Agrária de Pesquisa Agropecuária, 2006 $82 \mathrm{p}$.

EMPRESA BRASILEIRA DE PESQUISAAGROPECUÁRIA - EMBRAPA. Centro Nacional de Pesquisa de Solos. Sistema brasileiro de classificação de solos. Brasília: 1999. $412 \mathrm{p}$.

GOLDBERG, D. E.; LANDA, K. Competitive effect and response: hierarchies and correlated traits in the early stages of competition. J. Ecol., v. 79, n. 4, p. 1013-1030, 1991.

JACOBI, U. S.; FLECK, N. G. Avaliação do potencial alelopático de genótipos de aveia no início do ciclo. Pesq. Agropec. Bras., v. 35, n. 1, p. 11-19, 2000.

LEMERLE, D. et al. The potential for selecting wheat varieties strongly competitive with weeds. Weed Res., v. 36, n. 6, p. 505-513, 1996.

LEMERLE, D. et al. Genetic improvement and agronomy for enhanced wheat competitiveness with weeds. Aust. J. Agr. Res., v. 52, n. 5, p. 527-548, 2001
LEMERLE, D. et al. Incremental crop tolerance to weeds: a measure for selecting competitive ability in Australian wheats Euphytica, v. 149, n. 1-2, p. 85-95, 2006.

OGG JR., A. G.; SEEFELDT, S. S. Characterizing traits that enhance the competitiveness of winter wheat (Triticum aestivum) against jointed goatgrass (Aegilops cylindrica). Weed Sci., v. 47, n. 1, p.74-80, 1999

PASSINI, T. Competitividade e predição de perdas de rendimento da cultura de feijão quando em convivência com Brachiaria plantaginea (Link) Hitchc. 2001. 130 f. Tese (Doutorado em Agronomia) Escola Superior de Agricultura "Luiz de Queiroz", Piracicaba, 2001.

RADOSEVICH, S.; HOLT, J.; GHERSA, C. Weed ecology: implications for management. 2.ed. New York: Willey, 1997. $589 \mathrm{p}$

RIZZARDI, M. A.; FLECK, N. G. Métodos de quantificação da cobertura foliar da infestação de plantas daninhas e da cultura da soja. Ci. Rural, v. 34, n. 1, p. 13-18, 2004

SAS - Institute. Statistical Analysis System. User's guide 4.ed. Cary: 1989. 846 p.

SCHAEDLER, C. E. Potencial competitivo de cultivares de aveia com plantas concorrentes. 2008. $130 \mathrm{f}$. Dissertação (Mestrado em Fitossanidade) - Universidade Federal de Pelotas, Pelotas, 2008.

SEAVERS, G. P.; WRIGHT, K. J. Crop canopy development and structure influence weed suppression. Weed Res., v. 39, n. 4, p. 319-328, 1999.

SILVA, M. R. M.; DURIGAN, J. C. Períodos de interferência das plantas daninhas na cultura do arroz de terras altas. ICultivar IAC 202. Planta Daninha, v. 24, n. 4, p. 685-694, 2006.

SOBKOWICZ, P.; TENDZIAGOLSKA, E. Competition and productivity in mixture of oats and wheat. J. Agron. Crop Sci., v. 191, n. 3, p. 377-385, 2005.

VITTA, J. I.; FERNANDEZ QUINTANILLA, C. Canopy measurements as predictors of weed-crop competition. Weed Sci., v. 44, n. 3, p. 511-516, 1996. 